Volume 5

Issue 4 -- Patient Self-Management

Article 6

$10-29-2018$

\title{
Adapting Boot Camp Translation Methods to Engage Clinician/ Patient Research Teams Within Practice-Based Research Networks
}

\author{
Lyle J. Fagnan \\ Matthew J. Simpson \\ Jeanette M. Daly \\ LeAnn C. Michaels \\ David L. Hahn \\ Barcey T. Levy \\ Douglas H. Fernald \\ John M. Westfall \\ Donald E. Nease Jr.
}

Follow this and additional works at: https://aah.org/jpcrr

Part of the Community Health and Preventive Medicine Commons, Diseases Commons, Health and Medical Administration Commons, Health Services Research Commons, and the Primary Care Commons

\section{Recommended Citation}

Fagnan LJ, Simpson MJ, Daly JM, Michaels LC, Hahn DL, Levy BT, Fernald DH, Westfall JM, Nease DE Jr. Adapting boot camp translation methods to engage clinician/patient research teams within Practicebased research networks. J Patient Cent Res Rev. 2018;5:298-303. doi: 10.17294/2330-0698.1633

Published quarterly by Midwest-based health system Advocate Aurora Health and indexed in PubMed Central, the Journal of Patient-Centered Research and Reviews (JPCRR) is an open access, peer-reviewed medical journal focused on disseminating scholarly works devoted to improving patient-centered care practices, health outcomes, and the patient experience. 


\title{
Adapting Boot Camp Translation Methods to Engage Clinician/Patient Research Teams Within Practice-Based Research Networks
}

\author{
A Report From the INSTTEPP* Trial and Meta-LARC+ Consortium
}

\author{
Lyle J. Fagnan, MD, ${ }^{1}$ Matthew J. Simpson, MD, ${ }^{2}$ Jeanette M. Daly, PhD, RN, ${ }^{3}$ LeAnn C. Michaels, BS, ${ }^{1}$ \\ David L. Hahn, MD, ${ }^{4}$ Barcey T. Levy, MD, PhD, ${ }^{3}$ Douglas H. Fernald, MA, ${ }^{2}$ John M. Westfall, MD, ${ }^{2}$ \\ Donald E. Nease, Jr., MD² \\ ${ }^{1}$ Department of Family Medicine, Oregon Health \& Science University, Portland, OR; ${ }^{2}$ Department of Family Medicine, \\ University of Colorado School of Medicine, Aurora, CO; ${ }^{3}$ Department of Family Medicine, University of lowa, lowa \\ City, IA; ${ }^{4}$ Department of Family Medicine and Community Health, University of Wisconsin School of Medicine and \\ Public Health, Madison, WI
}

Purpose

Methods

Results

Conclusions

Keywords
Boot camp translation is a proven process to engage community members and health professionals in translating and disseminating evidence-based "best practices" models for health prevention and chronic illness care. Primary care practice improvement studies, particularly involving patient-driven change, as seen with self-management support (SMS), require engaged practice teams that include patients. Models of engagement such as boot camp translation may be effective.

Four geographically dispersed practice-based research networks (PBRNs) from the Meta-LARC consortium engaged 16 practices to form SMS implementation teams involving a clinician, care manager, and 2 patients in each team. Our study adapted the boot camp translation model to engage the implementation teams in describing patient SMS, studying the Agency for Healthcare Research and Quality's SMS Resource Library, and adapting and implementing self-management tools at each practice site. Testimonials and quotes were collected across the 4 PBRNs through a facilitated brainstorming discussion and consensus model at each PBRN kickoff meeting to address the focused question, "What do patients want and need in order to self-manage their chronic illnesses?"

Testimonials collected across the 4 PBRNs and participation levels indicated there was a high degree of engagement in the boot camp translation process across the PBRNs and the practices. Each PBRN developed themes expressed by patients and the practices regarding what patients want and need to self-manage their illnesses. Each practice selected, adapted, and implemented an SMS tool.

Results suggest that adapted boot camp translation was effective in guiding multiple practices to implement self-management support tools for the INSTTEPP trial. Additional study of the adapted boot camp translation process in practice quality improvement and practice redesign studies is needed. (J Patient Cent Res Rev. 2018;5:298-303.)
*Implementing Networks Self-management Tools Through Engaging Patients and Practices

†The Meta-Network Learning and Research Center is comprised of Duke Primary Care Research Consortium, lowa Research Network, Oregon Rural Practice-based Research Network, Quebec Practice-Based Research Network, State Networks of Colorado Ambulatory Practices and Partners, and Wisconsin Research and Education Network.

Correspondence: Lyle J. Fagnan, MD, Oregon Rural Practice-based Research Network, 3181 S.W. Sam Jackson Park Road, MC: L222, Portland, OR 97239-3098 (fagnan!@ohsu.edu)
$\mathrm{B}$ oot Camp Translation (BCT) was originally developed by eastern Colorado's High Plains Research Network and its community advisory council to engage community members and health professionals in translating and disseminating evidence-based "best practices" models for health prevention and chronic illness care across the community. ${ }^{1-3}$ The purpose of this report is to describe 
and recommend the adaptation of $\mathrm{BCT}$ as an effective tool for use by practice-based research networks (PBRNs) to engage family medicine practice teams and patients in quality improvement initiatives and for patient-centered primary care practice change, such as promoting patient self-management support (SMS).

The Implementing Networks Self-management Tools Through Engaging Patients and Practices (INSTTEPP) trial promoted the implementation of SMS tools by clinicians and care managers at small to mediumsized primary care practices across 4 states (Oregon, Colorado, Iowa, and Wisconsin). To promote patient engagement in behaviors that positively impact their illness, SMS is increasingly recognized as an important aspect of chronic disease management. At the core of effective SMS is inclusion and involvement of patients, clinicians, and practice care managers in determining effective tools for management. Thus, to develop a common understanding of SMS among health care providers and to evaluate the resources and tools needed to promote SMS, the INSTTEPP research team recognized the need for a team-based approach involving not only clinicians and nurse care managers but also patients to fully engage the practices.

We identified the BCT used in the INSTTEPP trial as an applicable methodology to engage 16 primary care practices in 4 PBRNs for our SMS implementation project. The design and study results are described elsewhere in this issue. ${ }^{4-7}$

\section{METHODS}

INSTTEPP was an 18-month long, Agency for Healthcare Research and Quality (AHRQ)-funded, stepped-wedge trial conducted in the Meta-Network Learning and Research Center (Meta-LARC). MetaLARC is a consortium of 6 PBRNs designated P30 Centers by AHRQ, 4 of which participated in this study: State Networks of Colorado Ambulatory Practices and Partners (SNOCAP), Oregon Rural Practice-based Research Network, Iowa Research Network, and Wisconsin Research and Education Network. ${ }^{8}$ From a candidate cadre of 24 practices in these 4 networks, we randomly selected 16 practices expressing interest in participation. The INSTTEPP study was registered at ClinicalTrials.gov (NCT02815020). ${ }^{9}$

Each participating practice formed an implementation team consisting of a clinician, a care manager, 2 patients, and others in the practice; this team informed local customization and implementation of SMS, as reported in detail elsewhere in this issue. ${ }^{6}$ Each of the 4 PBRN's BCT and SMS implementation teams was drawn from these participants, resulting in a group of 8 patients, 4 clinicians, 4 care managers, plus the

Table 1. INSTTEPP Boot Camp Translation (BCT) Process Adaptation

\begin{tabular}{|c|c|c|}
\hline Structure & HPRN BCT ${ }^{1}$ & INSTTEPP Adapted BCT \\
\hline Participants & $\begin{array}{l}16 \text { to } 20 \text {, primarily } \\
\text { community members }\end{array}$ & $\begin{array}{l}\text { Equal numbers of clinical practice } \\
\text { members and patients ( } 64 \text { individuals } \\
\text { from } 4 \text { practices) }\end{array}$ \\
\hline Kickoff & All-day retreat (6-7 hours) & 4 all-day retreats (6-7 hours each) \\
\hline Subsequent face-to-face meetings & 2 to 34 -hour meetings & $\begin{array}{l}\text { None. Practices held site-specific } \\
\text { visits or teleconferences involving } \\
\text { their clinic and patient teams. }\end{array}$ \\
\hline Focused teleconferences & 4 to 830 -minute calls & 3 to 430 -minute calls \\
\hline Practice-level facilitation & No & Yes \\
\hline PBRN coordination & Yes & Yes \\
\hline Other communication & Primarily email & Primarily email \\
\hline Participant time & 20 to 25 hours & 10 hours \\
\hline Duration & 4 to 12 months & 2 months \\
\hline
\end{tabular}

HPRN, High Plains Research Network; PBRN, practice-based research network. 
local PBRN's research team. Our study adapted the BCT model to engage these implementation teams in describing patient SMS, studying AHRQ's SMS Resource Library, ${ }^{10}$ and adapting and implementing SMS at each practice site (Table 1). All BCT processes were co-facilitated by the local PBRN research team and the SNOCAP research team.

Per the stepped-wedge design, ${ }^{11} \mathrm{BCT}$ was sequentially rolled out in 2014 in a randomized order across the 4 PBRNs, with Oregon starting in March, Wisconsin in May, Iowa in July, and Colorado in September. We made two key modifications to the original INSTTEPP BCT process. First, since INSTTEPP was specifically focused on the translation and development of SMS tools for implementation in primary care practices, we explicitly recruited clinicians and team members in primary care, but also sought equal representation and participation from practice staff and from patients (Table 1). Second, to meet the study timeline, we shortened the typical BCT process from 6 months to 2 months.

As is usual BCT practice, each PBRN held an all-day kickoff retreat at which the 4 SMS implementation teams addressed 2 focused questions: 1) What do patients want and need in order to self-manage their chronic illnesses? 2) What elements of AHRQ's SMS library/ toolkit can practices and patients use to address these needs? The in-person kickoff day began with a scientific presentation of evidence regarding SMS, followed by workstation introductions to individual elements in the library/toolkit. Guided by BCT experts from SNOCAP, the second half of the day was spent in facilitated brainstorming among participants and PBRN staff.

Defining SMS from the vantage points of both patients and the practices meant identifying the critical elements necessary for SMS to occur and, specifically, which of those elements would allow for successful implementation of the SMS tools. From the brainstorming sessions, each group identified a starting place for local adoption of these tools, which could then be further explored during subsequent BCT phone calls. Across the 4 PBRNs, directors, coordinators, and research team members also met by teleconference on a regular basis to share project updates and impressions.
We captured level of engagement by participant presence and contributions at the kickoff meeting and teleconferences. Contributions were assessed based on study team observations and examination of meeting summaries and minutes.

\section{RESULTS}

Engagement across the PBRNs and across primary care practices in this adapted $\mathrm{BCT}$ project was strong:

- The 4 networks engaged a total of 32 patients and 32 clinicians/care managers, forming 16 practice implementation teams.

- Of BCT participants, 45\% (16 clinicians/staff, 13 patients) participated in all BCT sessions.

- Each network completed all planned BCT phone calls, and 3 networks completed 1 additional call.

- Most practices completed some aspect of SMS tool implementation by study end (in full or piloting).

- Network personnel learned and implemented a new method of stakeholder engagement and have gone on to apply BCT methodology in practice change initiatives in other research studies.

Meeting summaries and minutes contained significant contributions across practice implementation team roles. It was the assessment of the research team that input was distributed across all roles. With such strong patient and practice staff participation, there was general agreement that the SMS kickoff retreats created a sense of community and equity across roles. Testimonials and quotes were collected across the 4 PBRNs. Two quotes best summarize 1) the outcome of patients as equals (ie, patient perspective): "All as equals? Yes. Nobody said, well, he's a doctor and what he has to say is more important than what I have to say. It was a level playing ground, and everybody took away something from someone." and 2) the outcome of team-based translation (ie, clinician perspective): "That study gave you an opportunity to have this conversation ... that was pretty unique, wasn't it? With the providers and the care managers and the patients - all in the same room."

At the kickoff meetings, each practice implementation team summarized the attributes of effective SMS. Across the PBRNs, from both patients and practice personnel, 5 important themes emerged about what patients want and need to self-manage their chronic 
illnesses: 1) shared responsibility; 2) empowerment; 3) respectful communication; 4) patient-centered quality measures; and 5) guidance consistent with patient preferences and evidence. Selected quotes from that PBRN kickoff meeting support these themes.

Shared responsibility addresses the underlying causes of the patient's health problems and requires the resources of major stakeholders, such as the patient, health coach, physicians, and other health care providers.

"Key is working with patients to help the patient develop own plan."

"MyChart (patient's own electronic medical record) is overwhelming for patients; the relationship with the patient is important to facilitate MyChart, appointments, etc."

Empowerment gives the patient permission to communicate their knowledge and understanding and treatment preferences.

"Focus on small accomplishments."

"Hold each other accountable."

Respectful communication involves listening to patients' stories and developing a deep understanding of their values and preferences.

"The doctor doesn't assume."

"Keep it simple."

"Man does not live by acronym alone."

Patient-centered quality measures include patient perceptions of how their illnesses are impacting their lives in terms of meeting their health goals.

"How do we go beyond the numbers?"

"You can't fix everybody, fix what you can."

Guidance consistent with patient preferences and evidence is resolution of a problem as preferred by patients but also is supported by research.

"Didn't have any help with financing for a health coach, so got some grants and just decided it was important to get coaching (beg, borrow, and steal)."

"The benefit of health coaching accrues to the health insurers, so the only way to make it work is to use the heath coach's entire time."
Implementing the $\mathrm{BCT}$ process in $\mathrm{PBRNs}$ and in their participating primary care practices requires considerable dedication of resources, time, and personnel. During the 2-month BCT implementation period, each of the 16 implementation teams maintained communications within their respective PBRN to arrive at a consensus about SMS tools to be implemented in their practices. This progress required considerable central staff support and time for planning and follow-up. Each conference call required 2 hours of preparation before the call and, subsequently, 1 hour for staff debriefing and creation of the summary of themes from the call for all participants. Each PBRN project team had a designated coordinator to schedule calls and call reminders for each participant. In addition, local network study coordinators and practice facilitators interacted with the practices in between calls.

\section{DISCUSSION}

BCT takes engagement and reach to another level, creating partnerships to address important health issues such as providing patient SMS tools. By implementing the BCT process in this way for the INSTTEPP study, the expanding circle of influence increased opportunities to engage practice teams and their members, including patients, to participate in quality improvement activities such as developing patient SMS. Figure 1 illustrates the expanding circle of influence created by the BCT process used in this initiative.

\section{BCT Provides Structure, Empowers Practice/ Patient Teams}

Effective change and improvement in clinical practice require the participation of functional practice teams. Engagement, involvement, and participation are critical to developing these teams but are difficult to achieve in typical PBRN studies in which central research staff engage each practice individually. In addition, patients are rarely involved in study implementation and planning. The INSTTEPP BCT process created new relationships and a broader learning community by building partnerships with clinical practice as well as with patient stakeholders from geographically dispersed communities. 


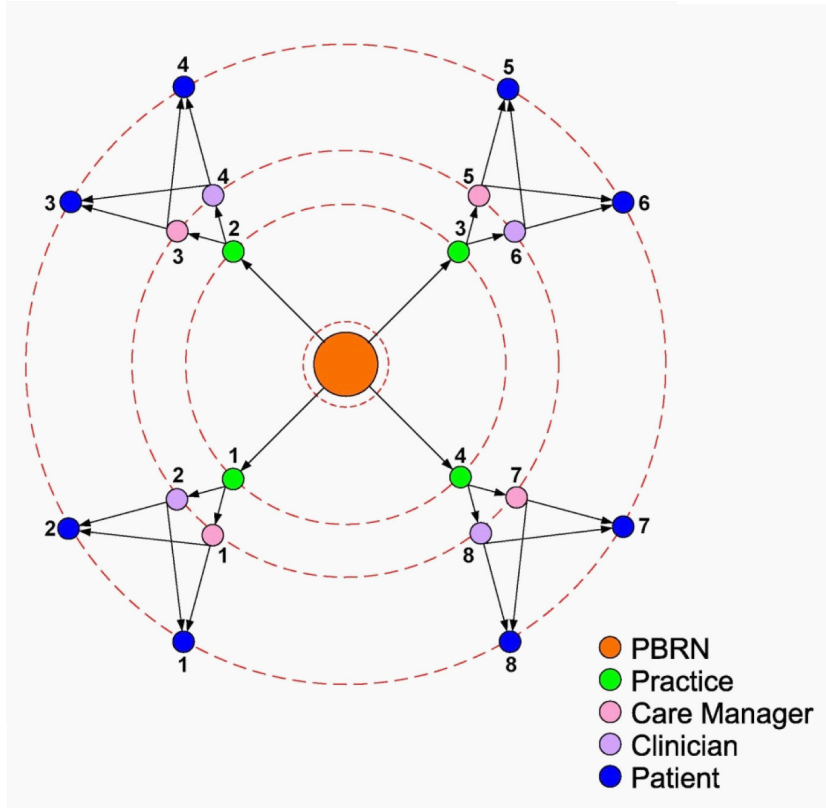

Figure 1. Illustration of how INSTTEPP extended the reach of practice-based research networks (PBRNs) beyond practices for engaging research teams that include clinicians and patients to create a shared learning community. Participants from each network included 4 practices, 4 clinician/care manager dyads, and 8 patients.

Within the prevailing structure of PBRNs, an academic research team traditionally serves in the role of knowledge broker between individual participating practices, creating a larger learning community. Within the context of the INSTTEPP trial, the BCT process allowed PBRNs to develop direct connections with participating constituents - clinicians, practice staff, and patients. At the practice level, relationships with patients prior to INSTTEPP were typically of a clinical nature. Significantly, throughout the BCT process, care team members and the patients they serve were present and informed one another's local implementation. This not only fostered connections between individuals across member practices but also allowed for additional connections within practices. Because patient engagement in clinical quality improvement is becoming increasingly common, and has shown promising results, ${ }^{12-14}$ the utilization of BCT within PBRNs provides an opportunity for networks to foster engagement within member practices to improve the quality of care.

\section{BCT Creates a Multistakeholder Learning Community}

Within the BCT learning environment, several INSTTEPP participants became SMS experts. This expertise spread from one practice to another as ideas were tested and refined during the BCT process. Figure 1 illustrates the reach of BCT to inform practices, clinicians, and staff beyond their individual practice implementation teams. This occurred in many ways: Practices and clinicians formed relationships with each other, patients formed relationships with each other (both within and between practices), and the relationships between practices and their patients changed as the focus expanded beyond only direct clinical care to include team planning and implementation of SMS. Furthermore, the PBRNs formed relationships with patients directly through the BCT process.

BCT does demand substantial investments in time by staff and patients alike, and the administrative coordination required to use the BCT process likely will vary according to the particular clinical setting in which it is used.

\section{CONCLUSIONS}

Adapted boot camp translation was successfully disseminated across 4 practice-based research networks to guide 16 primary care practices in developing patient self-management support tools. Results from the INSTTEPP trial suggest that BCT is an effective model to engage practice/patient teams in practice improvement studies. Because of the interactions observed at kickoff retreats, and informed by follow-up conference calls, our research team believes this BCT process is applicable to other quality improvement projects in clinical practice. As we did for INSTTEPP, the established BCT model should be adapted to accommodate the differences between community-based and practice-based research. From the testimonials and the high participation levels of clinic staff as well as patients, we learned that practices across our PBRNs found the time investment in BCT worthwhile and gained an enhanced understanding of the value of patients contributing to practice change and redesign. 


\section{Patient-Friendly Recap}

- Patients and clinic staff formed teams to assist with customizing and implementing self-management support tools in 16 primary care practices in Colorado, lowa, Oregon, and Wisconsin.

- A community process called boot camp translation was adapted for use by these teams, which created a sense of equity and led to strong participation from both patients and staff.

- Five themes on patients' self-management needs emerged: 1) shared responsibility; 2) empowerment; 3) respectful communication; 4) patient-centered quality measures; and 5) guidance consistent with patient preferences and evidence.

\section{Acknowledgments}

Mayo Clinic Health System (Tomah, WI); Milwaukee Health Services, Inc. (Milwaukee, WI); Northlakes Community Clinic (Iron River, WI); Richland Medical Center (Richland Center, WI); Family Medical Group, NE, P.C. (Portland, OR); Northwest Primary Care Sellwood Clinic (Portland, OR); Springfield Family Physicians (Springfield, OR); Winding Waters Clinic (Enterprise, OR); Akron Mercy Medical Clinic (Akron, IA); Red Haw Family Medical Center, P.C. (Chariton, IA); Family Medicine Clinic, University of Iowa Hospitals and Clinics (Iowa City, IA); Family Care Southwest (Littleton, CO); MidValley Family Practice (Basalt, CO); Westminster Medical Clinic (Westminster, CO); Yuma Clinic, (Yuma, CO). The authors gratefully acknowledge the editing and publication assistance from Ms. LeNeva Spires of Portland, Oregon.

\section{Author Contributions}

Study design: Fagnan, Westfall, Nease. Data acquisition or analysis: all authors. Manuscript drafting: Fagnan, Simpson, Michaels, Nease. Critical revision: Daly, Hahn, Levy, Fernald, Westfall.

\section{Conflicts of Interest}

None.

\section{Funding Sources}

This research was funded by Agency for Healthcare Research and Quality (AHRQ) grant 1R18HS022491-01. Infrastructure support (ie, Meta-LARC) was funded by AHRQ grant IP30HS021639-01.

\section{References}

1. Norman N, Bennett C, Cowart S, et al. Boot camp translation: a method for building a community of solution. J Am Board Fam Med. 2013;26:254-63. CrossRef

2. Westfall JM, Zittleman L, Felzien M, et al. Reinventing the wheel of medical evidence: how the boot camp translation process is making gains. Health Aff (Millwood). 2016;35:613-8. CrossRef

3. Allison $\mathrm{C}$, Zittleman L, Ringel M. et al. Translating the medical home into patient-centred language. London J Prim Care (Abingdon). 2014;6:124-30. CrossRef

4. Daly JM, Weiner Harrod T, Judge K, et al. Practice-based research networks ceding to a single institutional review board. J Patient Cent Res Rev. 2018;5:304-10.

5. Fernald DH, Simpson MJ, Nease DE Jr, et al. Implementing community-created self-management support tools in primary care practices: multimethod analysis from the INSTTEPP study. J Patient Cent Res Rev. 2018;5:267-75.

6. Nease DE Jr, Daly JM, Dickinson LM, et al. Impact of a boot camp translation intervention on self-management support in primary care. J Patient Cent Res Rev. 2018;5:256-66.

7. Simpson MJ, Daly JM, Fernald D, et al. How to translate selfmanagement support tools into clinical practice. $J$ Patient Cent Res Rev. 2018;5:276-86.

8. Agency for Healthcare Research and Quality. Meta-LARC: Meta-network Learning and Research Center. AHRQ Pub. No. 15-0025-4-EF, May 2015. https://pbrn.ahrq.gov/sites/default/ files/docs/page/Meta-Larc.pdf. Accessed July 30, 2018.

9. ClinicalTrials.gov. Implementing Networks Self-management Tools Through Engaging Patients and Practices (INSTTEPP). Last update posted 2016 Jun 28. https:/clinicaltrials.gov/ct2/ show/NCT02815020. Accessed July 31, 2018.

10. Agency for Healthcare Research and Quality. SelfManagement Support Resource Library. Content last reviewed April 2017. http://www.ahrq.gov/professionals/preventionchronic-care/improve/self-mgmt/self/sms_browse.html. Accessed July 30, 2018.

11. Brown CA, Lilford RJ. The stepped wedge trial design: a systematic review. BMC Med Res Methodol. 2006;6:54. CrossRef

12. Boivin A, Lehoux P, Lacombe R, Burgers J, Grol R. Involving patients in setting priorities for healthcare improvement: a cluster randomized trial. Implement Sci. 2014;9:24. CrossRef

13. Wiig S, Storm M, Aase K, et al. Investigating the use of patient involvement and patient experience in quality improvement in Norway: rhetoric or reality? BMC Health Serv Res. 2013;13:206. CrossRef

14. Nilsen ES, Myrhaug HT, Johansen M, Oliver S, Oxman AD. Methods of consumer involvement in developing healthcare policy and research, clinical practice guidelines and patient information material. Cochrane Database Syst Rev. 2006;(3):CD004563. rossRef

(C) 2018 Aurora Health Care, Inc. 